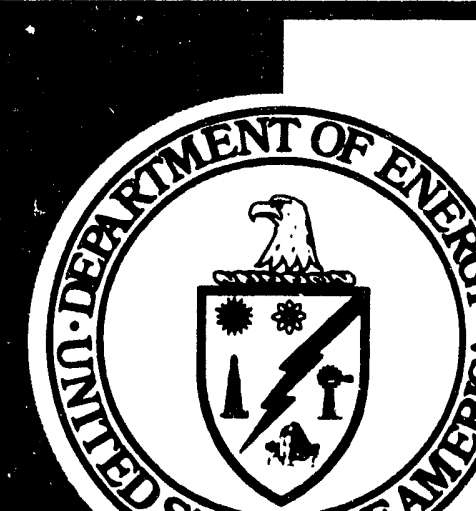

Office of Environmental Management Office of Technology Development

\title{
Pollution Prevention
}

Program

\section{Technology Summary}

\section{MASTER}

\section{February 1994}

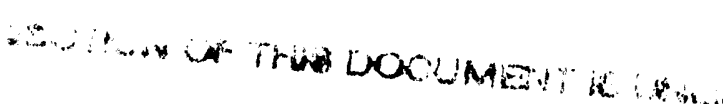




\section{TABLE OF CONTENTS}

OFFICE OF TECHNOLOGY DEVELOPMENT OVERVIEW .............................. iii POLLUTION PREVENTION PROGRAM OVERVIEW ....................................... v

1.0 DEPARTMENT OF ENERGY/U.S. AIR FORCE MEMORANDUM OF UNDERSTANDING PROGRAM OVERVIEW ….............................................. 3

1.1 Chlorinated Solvent Substitution Program ................................................. 5

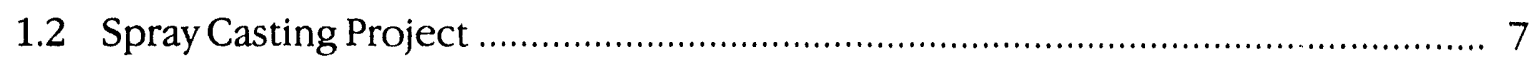

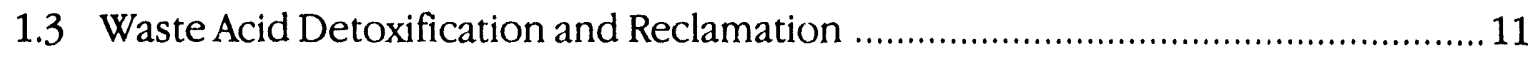

2.0 ENVIRONMENTALLY CONSCIOUS MANUFACTURING INTEGRATED

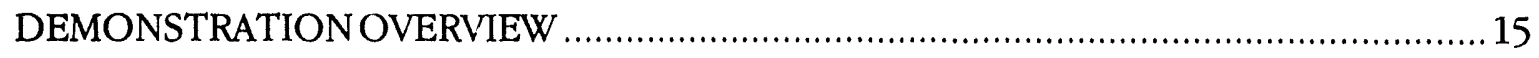

2.1 Integrated Environmentally Compatible Soldering Technologies ..................... 17

2.2 On-Line Monitoring of Volatile Organic Compounds .........................................21

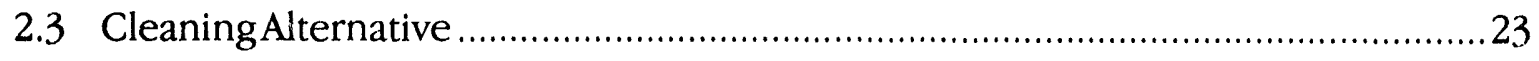

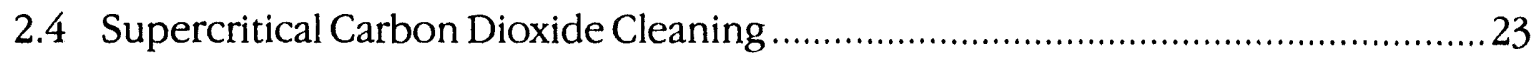

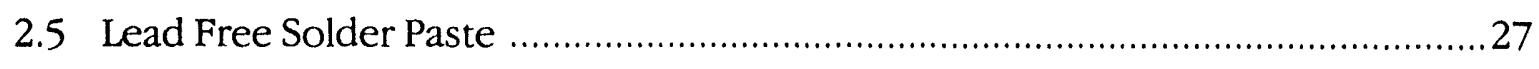

2.6 Validation of Environmentally Conscious Manufacturing Integrated Demonstration Hardware ..........................................................29

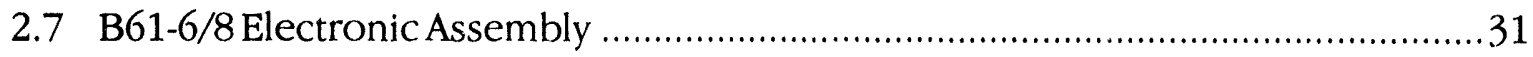

3.0 WASTE COMPONENT RECYCLE, TREATMENT, AND DISPOSAL

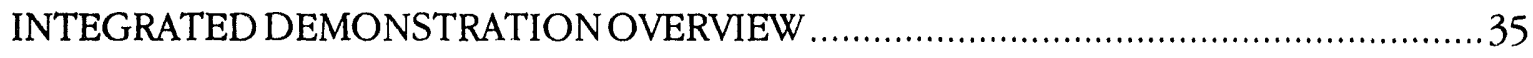

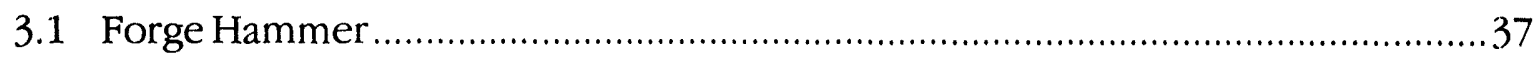

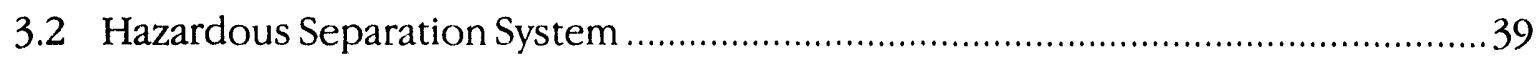

3.3 Advanced Treatment Technologies .................................................. 41

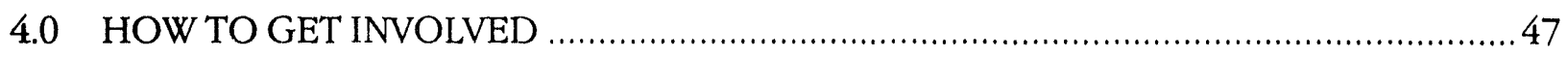

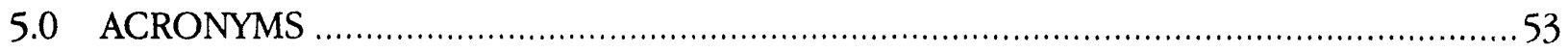




\section{FIGURES}

13.

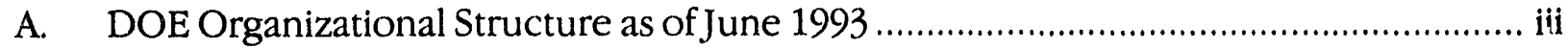

B. Office of Technology Development Organizational Structure as of June 1993 ............. iv

1.0. The industrial processes of the DOE/USAF MOU Program. ................................ 3

1.2. Controlled Aspiration Process. ......................................................................... 5

1.3. Modular Waste Acid Recovery System. ......................................................... 9

2.1. Environmentally Conscious Manufacturing Integrated

Demonstration Printed Wiring Boards. .............................................................. 16

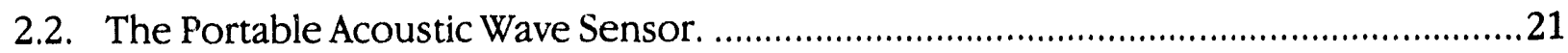

2.4. Ideal Supercritical Carbon Dioxide Cleaning System. ........................................23

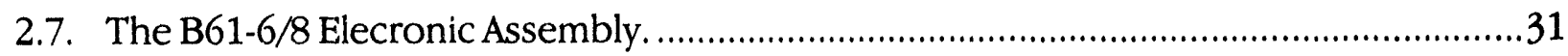

3.0a. Waste Component Recycle, Treatment, and Disposal Integrated Demonstration Directions Treatment Technology Wiring Diagram ..........................33

3.0b. Disassembled Sandia-designed Nuclear Weapon. .................................................33

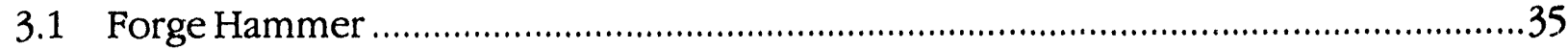

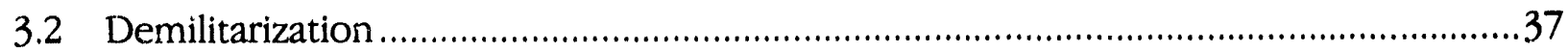

3.3a. Electronic components before and after thermal treatment processes. .....................39

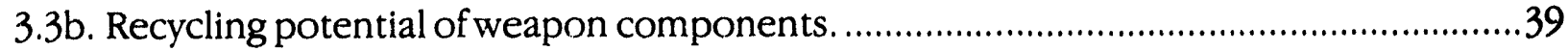




\section{OFFICE OF TECHNOLOGY DEVELOPMENT OVERVIEW}

The Department of Energy (DOE) established the Office of Technology Development (EM-50) (OTD) as an element of Environmental Restoration and Waste Management (EM) in November 1989 (see Figure A). The organizational structure of EM-50 is shown in Figure B.

EM manages remediation of all DOE sites as well as wastes from current operations. The goal of the EM program is to minimize risks to human health, safety and the environment, and to bring all DOE sites into compliance with Federal, state, and local regulations by 2019. EM-50 is charged with developing new technologies that are safer, faster, more effective and less expensive than current methods.

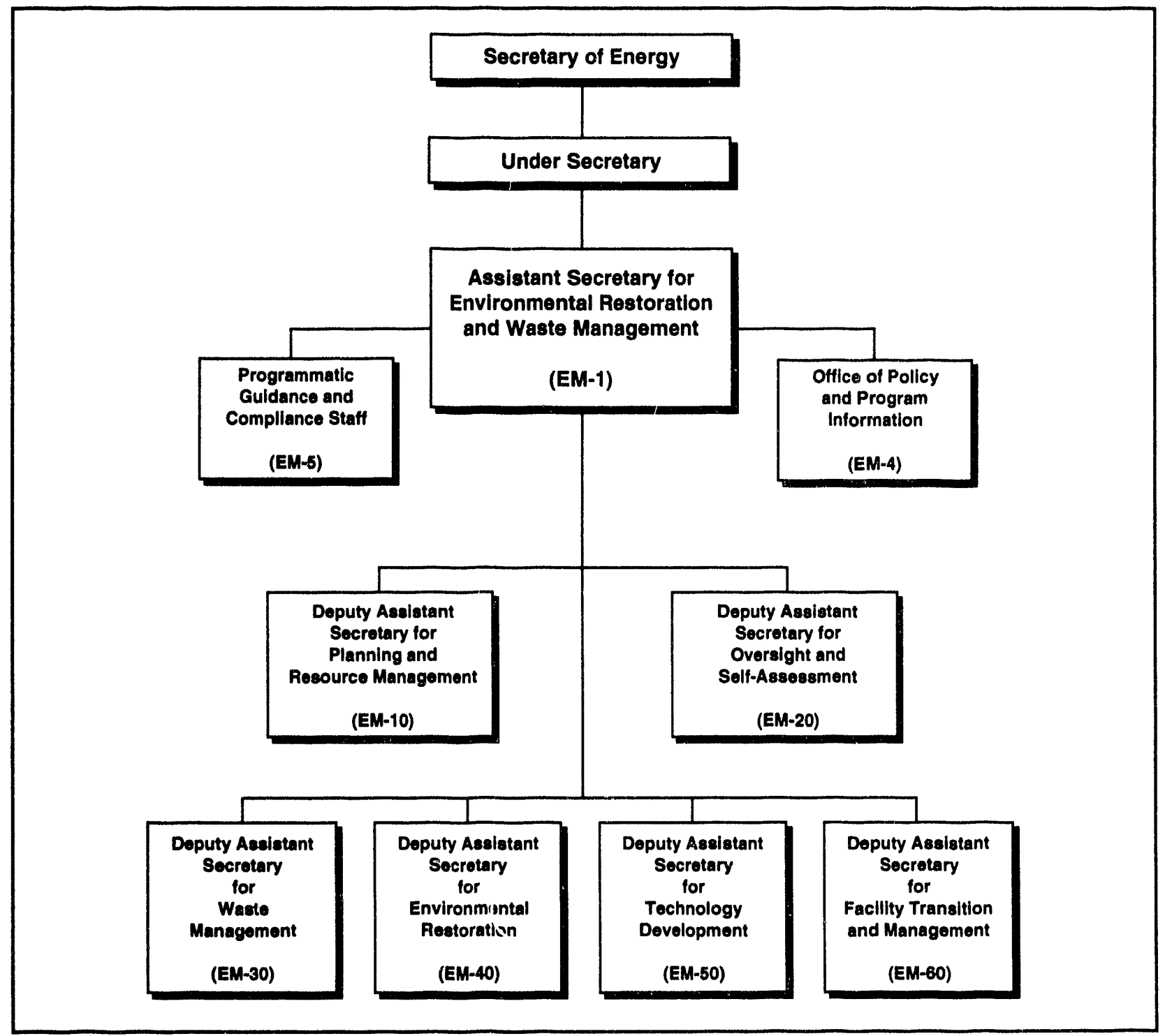

Figure A. DOE Organizational Structure as of June 1993. 
In an effort to focus resources and address opportunities, EM-50 has developed Integrated Programs (IP) and Integrated Demonstrations (ID). An Integrated Program focuses on technologies to solve a specific aspect of a waste management or environmental problem and it can be either unique to a site or common to many sites. An Integrated Program supports applied research to develop innovative technologies in key application areas organized around specific activities required in each stage of the remediation process (e.g., characterization, treatment, and disposal).

An Integrated Demonstration is the cost-effective mechanism that assembles a group of related and synergistic technologies to evaluate their performance individually or as a complete system in correcting waste management and environmental problems from cradle to grave.

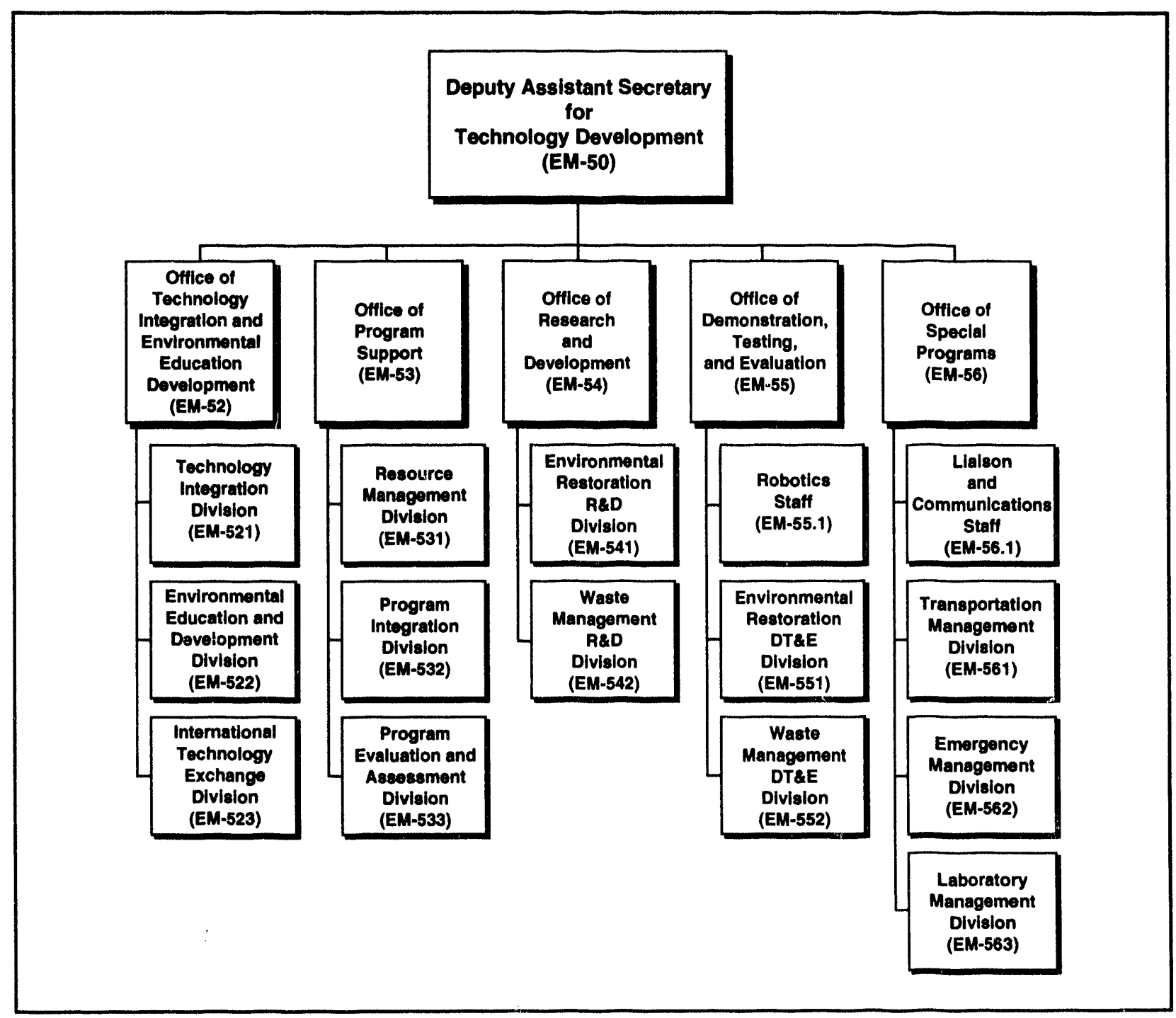

Figure B. Office of Technology Development Organizational Structure as of June 1993. 


\section{POLLUTION PREVENTION PROGRAM OVERVIEW}

OTD carries out national technology development programs targeted at meeting the evolving: technology needs of EM. The Demonstration, Testing, and Evaluation Division (DT\&E) (EM-55) was established by EM-50 to serve as an important tool for expediting the transition of operable technology solutions to meet waste operations and remediation customer needs.

DOE has established a national Research, Development, Demonstration, Testing, and Evaluation (RDDT\&E) Program for pollution prevention and waste minimization at its production plants. During FY89/90, EM, through OTD, established comprehensive, pollution prevention technical support programs to demonstrate new, environmentally-conscious technology for production processes. The RDDT\&E program now entails collaborative efforts across DOE.

Recognizing that pollution prevention is DOE's preferred approach to meet its environmental responsibilities, RDDT\&E supports an integrated approach through the development and demonstration of technologies that focus on process modifications, material substitutions, recycling and reuse and energy efficiency in support of applicable Federal, state and local environmental regulations. Advances in this area have the potential to provide significant cost savings through efficient use of raw materials and lower costs associated with waste storage, treatment, and disposal. In addition, they have the potential to stimulate U.S. competitiveness and economic growth through the growth of a "clean" technology industry.

The Pollution Prevention Program is currently supporting three major activities:

- The DOE/U.S. Air Force Memorandum of Understanding (DOE/USAF MOU) Program is a collaborative effort to utilize the combined resources of DOE and the Department of Defense (DoD), eliminate duplication of effort in developing technologies, and to facilitate technology solutions aimed at reducing waste through process modification, material substitution or recycling.

- The Waste Component Recycle, Treatment and Disposal Integrated Demonstration (WeDID) will develop recycle, treatment, and disposal processes and associated technologies for use in the dismantlement of non-nuclear weapons components, to support U.S. arms treaties and policies. This program will focus on meeting all security and regulatory requirements (with additional benefit to the commercial electronics industry).

- The Environmentally Conscious Manufacturing Integrated Demonstration (ECMID) will effectively implement ECM technologies that address both the needs of the DOE Complex and U.S. electronics industry, and encourage strong interaction between DOE and U.S. industry. The ECMID will also develop life cycle analysis tools that will aid the decisionmakers in selecting the optimum process based on the tradeoffs between cost and environmental impact. 
Department of Energy/

U.S. Air Force

Memorandum of Understanding

\section{Section 1.0}




\subsection{DEPARTMENT OF ENERGY/U.S. AIR FORCE MEMORANDUM OF UNDERSTANDING PROGRAM OVERVIEW}

The DOE/USAF MOU Program was formed to jointly reduce waste generation in common areas and avoid duplication of research efforts. The Program promotes the development of pollution prevention technologies, such as material substitution and advanced manufacturing techniques, to reduce or eliminate the generation of hazardous waste. Joint agency development permits leveraging of Federal funds.

DOE/USAF MOU will cover all phases involved in industrial processes (see Figure 1.0). It will help expedite future selection and implementation of the best technologies and show immediate and longterm effectiveness for DOE and United States Air Force (USAF) sites. The Program will conduct performance comparisons of available technologies under field conditions based on effectiveness with respect to the technology itself, risk reduction, and general acceptability.

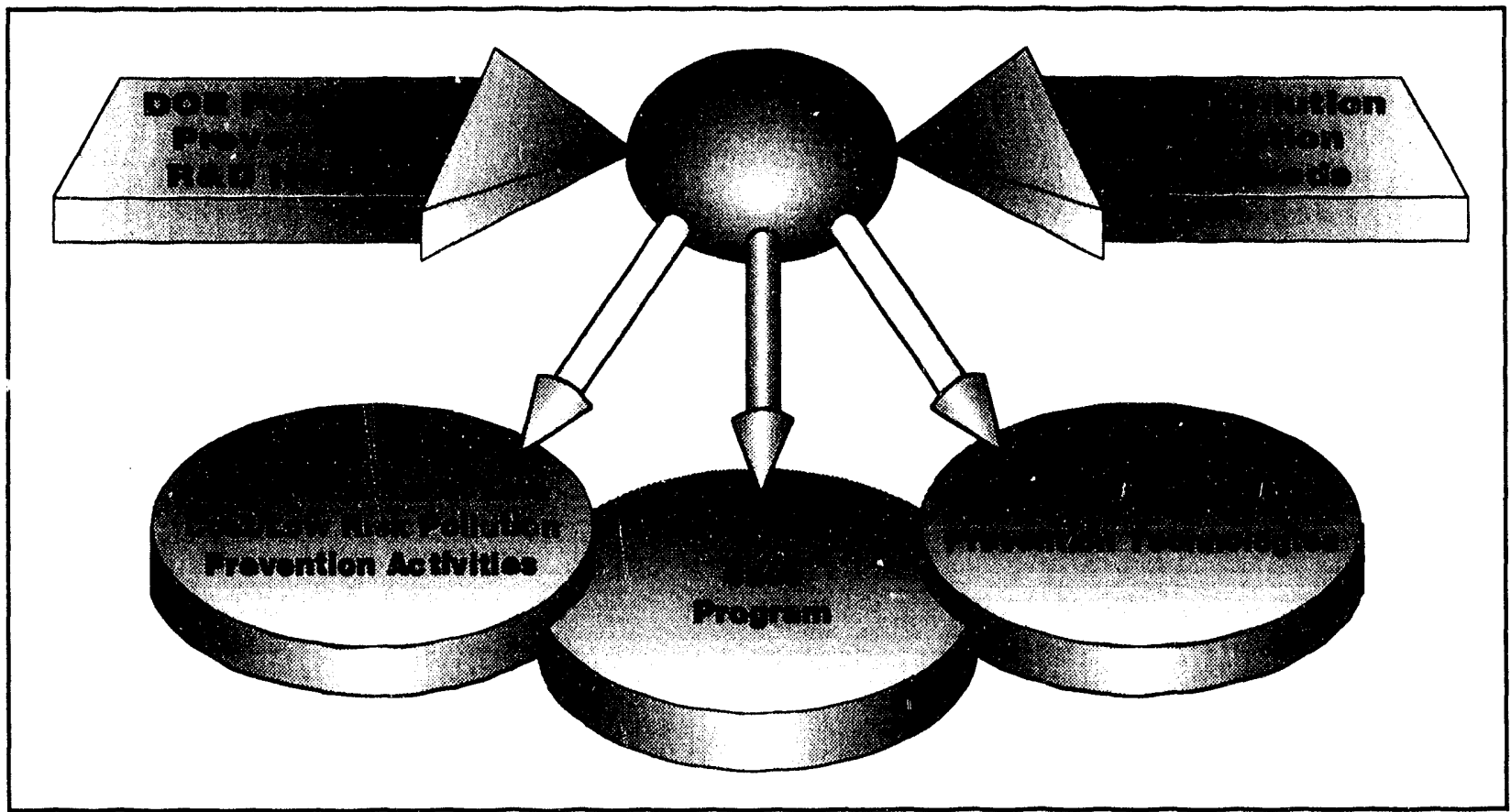

Figure 1.0. The industrial processes of the DOE/USAF MOU Program. 
Several projects have contributed to the establishment of a formal program between DOE and the USAF. Since the early 1980's, the Air Force Civil Engineering Support Agency (AFCESA), formerly the Air Force Engineering Services Center (AFESC), requested that the Idaho National Engineering Laboratory (INEL) perform a variety of environmental projects. These included:

- Sodium Sulfide/Ferrous Sulfate Metals

Precipitation;

- Metals Recovery from Sludge;

- Bicarbonate of Soda Stripping;

- Noncyanide Metal Strippers; and

- Biodegradable Solvent Substitution.

In 1988, a Memorandum of Understanding (MOU) was signed between EM and the Laboratory Commander of the AFESC. This MOU stated that the two organizations would jointly develop mutually beneficial environmental technologies, promote technology information exchange, and assist in arranging interlaboratory/industry partnerships.

FY92 was the first year for the formal program. The projects emphasize pollution prevention by addressing wastes regulated by the Resource Conservation and Recovery Act (RCRA), the Clean Air Act (CAA), and the Clean Water Act (CWA). The projects are summarized in the following sections. 


\subsection{CHLORINATED SOLVENT SUBSTITUTION PROGRAM}

\section{TASK DESCRIPTION}

The objective of this program is to assist in the effective replacement of the toxic halogenated solvents currently used in DOE Defense Program facilities. Solvents and cleaners are used for removing several types of contaminants before repairing or electroplating parts. Halogenated solvents are used primarily for metal cleaning and paint stripping and pose a variety of safety and environmental problems. In addition to threatening human health, these solvents generate hazardous wastes and toxic air emissions. This program developed standardized methods to identify alternative products that are safe to both the workers and the environment, and are at least as efficient as current solvents. The program developed a mechanism to make the resulting data available to all users. Therefore, solvents are being evaluated according to various criteria, such as cleaning/stripping efficiency, corrosion, toxicity, air emissions, compatibility with non-metals, and recyclability; and the resulting data were incorporated into an easily accessible "living" database for end users. In addition to the database, this data is maintained in a handbook that provides an efficient, easily accessible, electronic utilization database containing standardized test results for chlorinated solvent substitutes.

\section{TECHNOLOGY NEEDS}

Substitutes for chlorinated solvents are needed by $\mathrm{DOE}$ and the industrial community, both nationally and internationally. The need is driven by tightening environmental regulations including RCRA, CWA, and CAA. These regulations preclude the use of some chemicals and restrict the use of various halogenated hydrocarbons because of their atmospheric-ozone depleting effects, as well as their cancer-related risks. DOE and industry are facing serious pollution problems in soil, water, and air caused by the use of toxic solvents. This technology will prevent pollution from occurring and reduce the need for future environmental restoration.

\section{ACCOMPLISHMENTS}

- Tested over 300 substitute solvents and established a database to house all test data for cleaning performance and corrosion properties.

- Held the 3rd Annual International Workshop on Solvent Substitution.

- Demonstrated and evaluated prototype solvent substitution handbook with 50 test users.

- Transferred technology to Safe Solvents Testing Laboratory.

\section{COLLABORATION/TECHNOLOGY TRANSFER}

Industry participation has been obtained through three Solvent Substitution Workshops, resulting in the following industry partnerships: 


\section{2 \\ SPRAY CASTING PROJECT}

\section{TASK DESCRIPTION}

This task is developing a new manufacturing and repair process to replace electroplating by applying coatings directly onto substrates, and spraying the molten coating material through a specially designed nozzle. The process utilizes a controlled aspiration process to spray liquid metal into a mold for near-net shape forming applications or on a substrate as a protective coating (see Figure 1.2). This technology has a dual application for both DOE and the Air Force.

The DOE's Office of Technology Development is supporting waste minimization efforts in the fabrication of special nuclear materials. This portion of the project involves spray forming various DOE components to near-net shapes. Spray forming greatly reduces the amount of waste generated during the fabrication of these components compared to existing techniques. Despite a dramatic decrease in production requirements at DOE Defense Program facilities, manufacturing needs still exist. Work is continuing to complete installation and testing of the robotics arm, fabrication and evaluation of near-net shape components, and spraying and evaluation of coatings for corrosion protection.

The Air Force effort is directed at replacement of chromium electroplating as a repair/refurbishment technique on aviation parts. Chromium plating processes are being replaced by a thermally sprayed coating of equal or superior mechanical and physical properties. The coating portion of this project is being demonstrated at Robbins Air Force Base (AFB) in Warner-Robbins, Georgia. The USAF portion of the project is sponsored by the USAF Civil Engineering Support Agency at Tyndall AFB. Design and fabrication continues of pilot equipment for installation at Robbins AFB, as does verification testing of selected Air Force parts.

\section{TECHNOLOGY NEEDS}

The Spray Casting technology will avoid or eliminate waste as a result of material or process changes from existing methods, and will reduce the generation of waste material at the source. Downsizing, decontamination, and decommis-

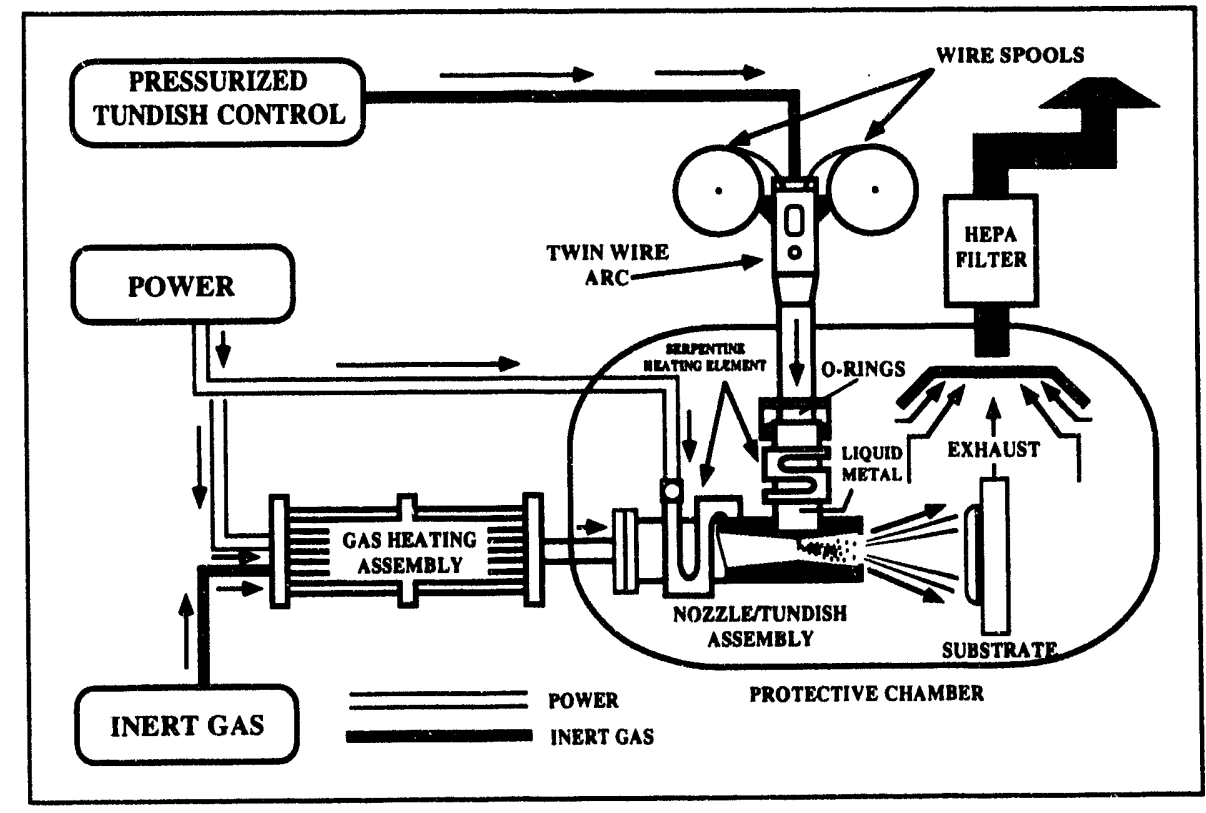

Figure 1.2. Controlled Aspiration Process. 
For further information, please contact:

\section{Ronald Glovan}

Principal Investigator

MSE, Inc.

(406) 494-7287

\section{Gary Staats}

Technical Program Officer

DOE-PETC

(412) $892-5741$

\section{Anthony Malinauskas}

Technical Program Manager

MMES

(615) 576-1092

\section{Steven Brown}

Project Manager

EG\&G Idaho

(904) 283-6195 


\section{TASK DESCRIPTION}

This project is designing, fabricating, assembling, testing, and installing a prototype acid recovery system (see Figure 1.3). It will deal with the large quantities of metal-bearing spent acids produced by electroplating, surface finishing, and chemical milling/dissolution operations common to DOE and USAF manufacturing and chemical processes. The task includes technical analysis of spent acids and chemicals, and laboratory testing of DOE, industrial, and USAF process acids. It is developing engineering design data, generating a conceptual design of a prototype system, and conducting initial testing of the prototype system at PNL with DOE spent acids. It is conducting demonstration testing of the prototype system at Boeing Aerospace, installation and final acceptance testing at a USAF or DOE facility, and engineering and technical support for operation of the system.

\section{TECHNOLOGY NEEDS}

Large quantities of metal-bearing spent acids are produced by electroplating, surface finishing, and chemical milling/dissolution operations common to DOE and USAF manufacturing and chemical processes. In addition, spent acids are widespread throughout U.S. private industry with over 15,000 companies generating over 8 billion pounds of metal-bearing spent acids each year. At the Los Alamos National Laboratory (LANL), ongoing milling operations of uranium metal generate 1000-2000 gallons of spent nitric, hydrofluoric, and sulfuric acids each month.

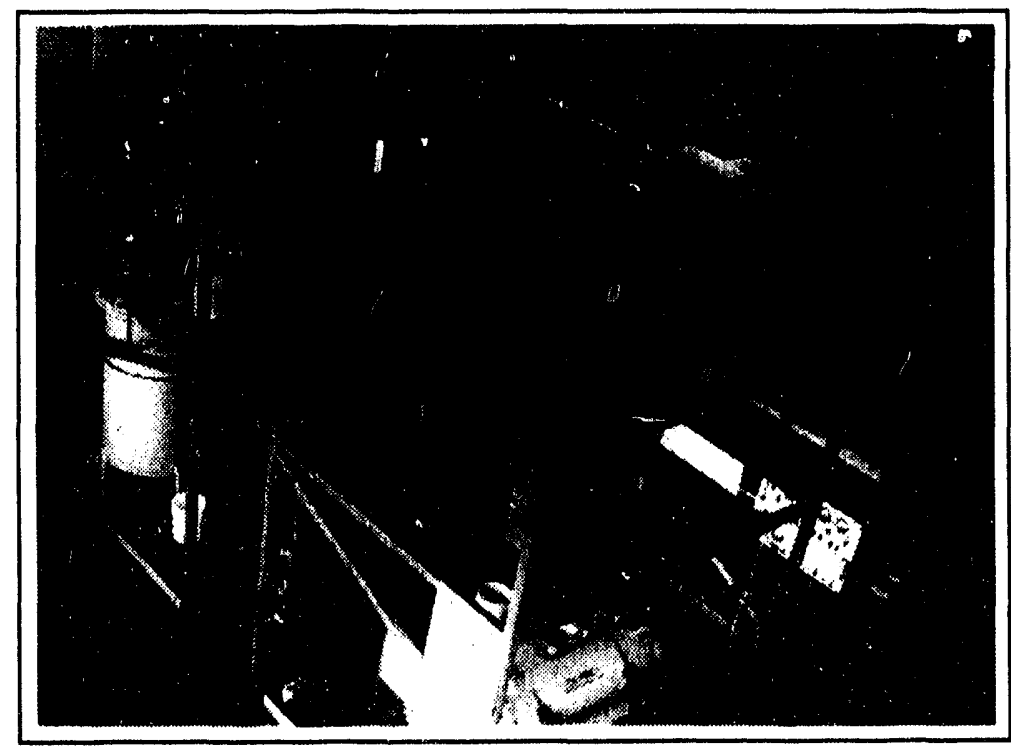

Figure 1.3. Modular Waste Acid Recovery System.

Further, treating the 60 million gallons of tank waste at the Hanford site is expected to require millions of gallons of nitric and other acids that must be effectively recycled and reused.

\section{ACCOMPLISHMENTS}

- Visited Warner-Robbins and Oklahoma City Air Force Logistics Center, Boeing Defense and Space Group, and LANL.

- Completed collecting preliminary process information. 
- Completed technology information profile.

- Conceptual design of 5-gallon per hour system in progress.

- Conceptual design for the industrial prototype has been completed and the task is on track to complete demonstration testing in FY94 with surrogate DOE acids at the Hanford site, spent acids from active plating solutions at Boeing Aerospace and final installation at Tinker Air Force Base.

- Process licensed to Viatec Recovery Systems.

- Received 1993 Federal Laboratory Consortium Award for Excellence in Technology Transfer.

- Received special recognition from Chemical Processing magazine's Vaaler Award program significant developments contributing to efficient, cost-effective operations in the chemical process industry.

\section{COLLABORATION/TECHNOLOGY TRANSFER}

This project is being jointly developed with DOE laboratories and private industry. Technology has been licensed in partnership with Viatec Recovery Systems to design and manufacture a acid recovery system. This project was included in a top proposal to National Technology Transfer Center in West Virginia linking Federai laboratories with private companies. Cost savings to private industry based on 100,000 gallons per year is estimated at $\$ 150,000$ $\$ 300,000$ per year.

\section{For further information, please contact:}

\section{Evan Jones}

Principal Investigator

Pacific Northwest Laboratory

(509) 372-0662

\section{Steven Slate}

Technical Program Manager

Pacific Northwest Laboratory

(509) 375-3903 
Environmentally Conscious Manufacturing Integrated Demonstration Overview

Section 2.0 


\subsection{ENVIRONMENTALLY CONSCIOUS MANUFACTURING INTEGRATED DEMONSTRATION OVERVIEW}

The Environmentally Conscious Manufacturing Integrated Demonstration (ECMID) is being performed jointly by Sandia National Laboratory (SNL) and Allied Signal at the Kansas City Plant (AS-KCP). This Integrated Demonstration was started in FY90 to implement a total systems approach to ECM that will lead to cost-effective elimination of waste in the manufacture of electronic and electromechanical components for nuclear weapons. System issues, such as cost, materials compatibility, and balanced process integration can not be addressed through individual technology programs. Instead, designers, production engineers, material engineers, system engineers, and process development engineers must be included in all phases of the design and manufacturing process. By means of the ECMID, cleaning, joining, solvent substitution, coating, metal finishing, process control, packaging, and assembly will be treated as interdependent processes to minimize the generation of hazardous wastes in electronic manufacturing. This Integrated Demonstration also seeks to reduce the risk to production workers and the cost of electronics production. This demonstration is being conducted in close collaboration with DOE Defense Programs and will draw upon the expertise found within the DOE Complex and private industry. 


\section{1 \\ INTEGRATED ENVIRONMENTALLY COMPATIBLE SOLDERING TECHNOLOGIES}

\section{DESCRIPTION}

The goal of this program is to characterize and demonstrate alternative soldering technologies that can be applied towards reducing solvent use and the subsequent volume of chemical waste generated during soldering of microelectronics assemblies. The Integrated Environmentally Compatible Soldering effort covers several technologies (materials and processes) that address the ozone depletion and waste stream problems.

Fluxless and "no clean" soldering covers a wide variety of technologies that utilize various "clean" or reducing atmospheres to either maintain or produce a solderable base surface. Vacuum, inert or reducing gas, reactive plasma, and activated acid vapor atmospheres have been applied to fluxless soldering. These atmospheres restrict the supply of oxygen to the work piece during the heating and soldering operations. The "no clean" solder concept typically couples controlled atmospheres with the use of a low- solids flux. Flux residues are generally negligible. Work being conducted at SNL has shown that the gas species (molecular, atomic, or ionic) has a significant effect on the rate of oxide reduction and subsequent solder wetability. Although thermodynamic data suggests that the reduction of metallic oxides in hydrogen or vacuum is feasible at typical soldering temperatures, 200$300^{\circ} \mathrm{C}$, the rate of reaction is very low. Reactive gases have a greater potential for effectively reducing surface oxides. SNL has characterized the effect of reactive gases on directly soldering metallic substrates.
The use of protective coatings (metallizations and organic preservation/inhibitors) can reduce the need for a flux. Nonoxidizing surfaces, such as gold or other noble alloys, have a long history of being readily wet by solder without fluxing. A thick metallization layer is generally required to guarantee a nonporous surface barrier that will adequately protect the wettability of the underlying base metal. However, the thickness of gold must be carefully controlled when using tinbased solder alloys. Gold reacts with tin to form a brittle intermetallic that could consequently embrittle a solder joint if excess gold is applied. Conversely, a thin, porous layer of gold might expose the underlying metal that would be susceptible to oxidation or corrosion in a poorly controlled storage environment. These porous metallizations can be protected during storage by applying organic inhibitors. SNL has collaborated with the University of California at Berkeley to characterize the effects of disposition method, surface roughness, and micro-structure of gold, nickel and copper surfaces on fluxless wetting. The State University of New York at Stony Brook has studied the bonding behavior of organic inhibitors on metallic surfaces. Results from the two university programs have been used by SNL to design metallization and inhibitor systems that facilitate fluxless soldering or allow the use of more environmentally-compatible fluxes.

Laser ablative cleaning involves the use of very short pulses of high peak power laser radiation to rapidly heat and vaporize microscopically thin layers of oxidized metal surfaces in an inert gas environment. The vaporized material quickly condenses on contact with the cooler ambient gases forming submicron particles that are eas- 
ily transported from the "clean" surface by a flowing gas stream. These waste particles can be collected with a submicron filter canister. A Qswitched pulsed laser beam can be mechanically scanned across the faying surface to not only ablate the surface, but to also directly wet it without fluxing. Secondary heating can be used to also make the solder joint. The cover gas prevents recontamination of the cleaned surfaces. SNL has recently developed a laser ablative fluxless soldering (LAFS) process that yieids high quality metallurgical bonds without use of reactive chemicals. The combination of high spatial resolution and low thermal impact makes LAFS an attractive process for application on microcircuits and high density printed circuit boards (see Figure 2.1).

Wetting evaluations have been conducted with LAFS and the experiments have been highly successful. Aluminum, copper and nickel surfaces, typically difficult metals to wet without fluxing, were directly wet using LAFS.

Water soluble and low solids ("no clean") fluxes are alternatives to fluxless soldering processes. Although these fluxes require some level of cleaning after soldering, electronic assemblies can be cleaned by more environmentally compatible methods (e.g. alcohol or aqueous based cleaners). Since most soldering lines have been set up for rosin-based fluxes, work must be done to define the working limits of the alternative fluxes. The newer fluxes are generally more sensitive to the soldering parameters and have a narrower operating range. SNL has been working with Allied Signal to integrate water soluble and low solids fluxes into ECM practice. A nontoxic, nonflammable, citric acid based flux has especially demonstrated potential.

\section{TECHNOLOGY NEEDS}

Chemical fluxes are typically used during conventional electronic soldering to enhance solder wettability. Most fluxes contain very reactive, hazardous constituents that necessitate special storage, handling, and cleaning procedures. Corrosive flux residues can also compromise product reliability if left on the soldered part. The residues are generally removed with CFC or other hazardous solvents that have been linked to either ozone depletion or waste stream generation. Alternative materials and processes are being developed to lessen the dependence on these solvents, many of which are being phased out to meet environmentally-driven restrictions. SNL has developed a variety of soldering technologies that facilitate the reduction of solvent

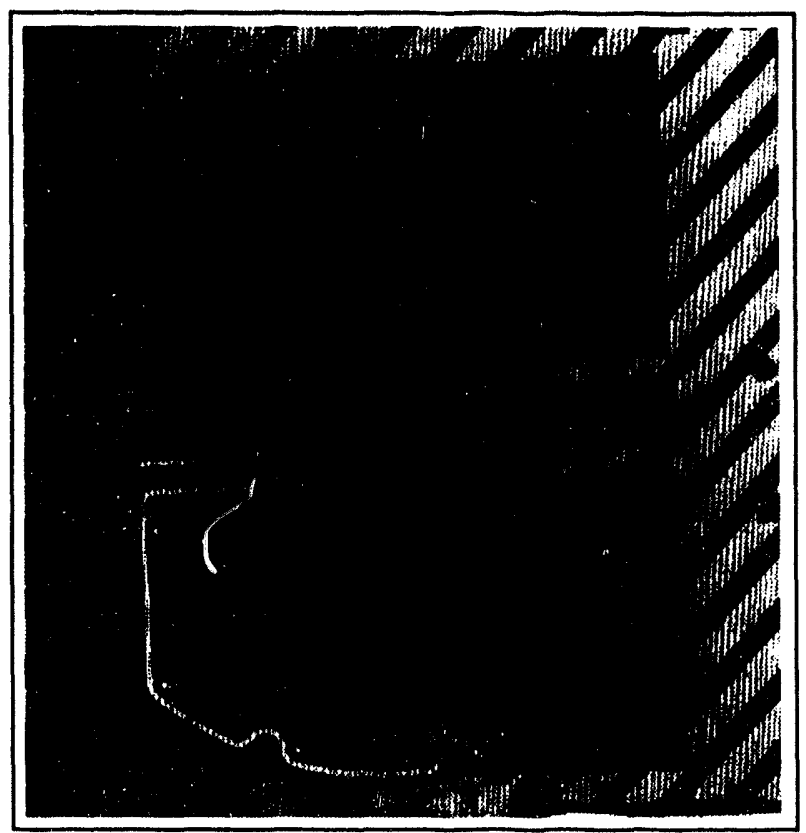

Figure 2.1. ECMID Printed Wiring Boards.

use and the subsequent volume of chemical waste generated during electronic soldering. Since there is no single process that can be universally applied to the waste minimization 
problem, these technologies are intended as complements to each other and should not be viewed as competing processes under the given constraints.

\section{ACCOMPLISHMENTS}

- Demonstrated the feasibility of applying controlled atmospheres, metallizations, organic inhibitors, lasers, and ultrasonic soldering as fluxless or "no flux" soldering operations.

- Demonstrated pretinning process using laser ablative and ultrasonic soldering technique.

- Demonstrated water soluble and lowsolid flux selection, laser soldering of an integrated circuit, and inert/activated atmospheres soldering.

- Selected water-soluble and low-solids fluxes for demonstration.

- Demonstrated laser ablative cleaning at the Kansas City Plant.

\section{COLLABORATION/TECHNOLOGY TRANSFER}

The technologies will be available to DOE design and production facilities, subcontractors, other government agencies, and the commercial sector. Technology transfer will be handled through SNL's Technology Transfer Center. Site visits, technical presentations, and documentation in open literature will also facilitate technology transfer.

For further information, please contact:

\section{Michael Hosking}

Principal Investigator

Sandia National Laboratory

(505) 845-8401

\section{George C. Allen}

Technical Program Manager

Sandia National Laboratory

(505) 844-9769 


\section{ON-LINE MONITORING \\ OF VOLATILE ORGANIC COMPOUNDS}

\section{TASK DESCRIPTION}

Sandia National Laboratory's program for online monitoring of volatile organics for waste minimization involves development, demonstration, and fielding of portable acoustic wave sensor (PAWS) systems based on a technique for obtaining chemical discrimination using a single sensor by monitoring both the wave velocity and the wave attenuation (see Figure 2.2). Program activities include identification of high priority needs for chemical monitoring, development of selective and sensitive acoustic wave sensors for these applications, and integration of these sensors into systems containing automated data acquisition and analysis techniques, and real-time reporting of chemical concentrations. These capabriicies are being applied to inonitor process lines, exhaust systems, and work-place environments. The chemical information provided by these systems will be used to document emissions to the environment and prevent discharging above the EPA limits as well as to modify engineering parameters and improve process control to increase efficiency and minimize waste.

\section{TECHNOLOGY NEEDS}

Ratification of the Montreal Protocol will result in significant reductions in the production and usage of Chloroflurocarbons (CFC) and chlorohydrocarbons (CHC). EPA has indicated that most, if not all, halogenated solvents

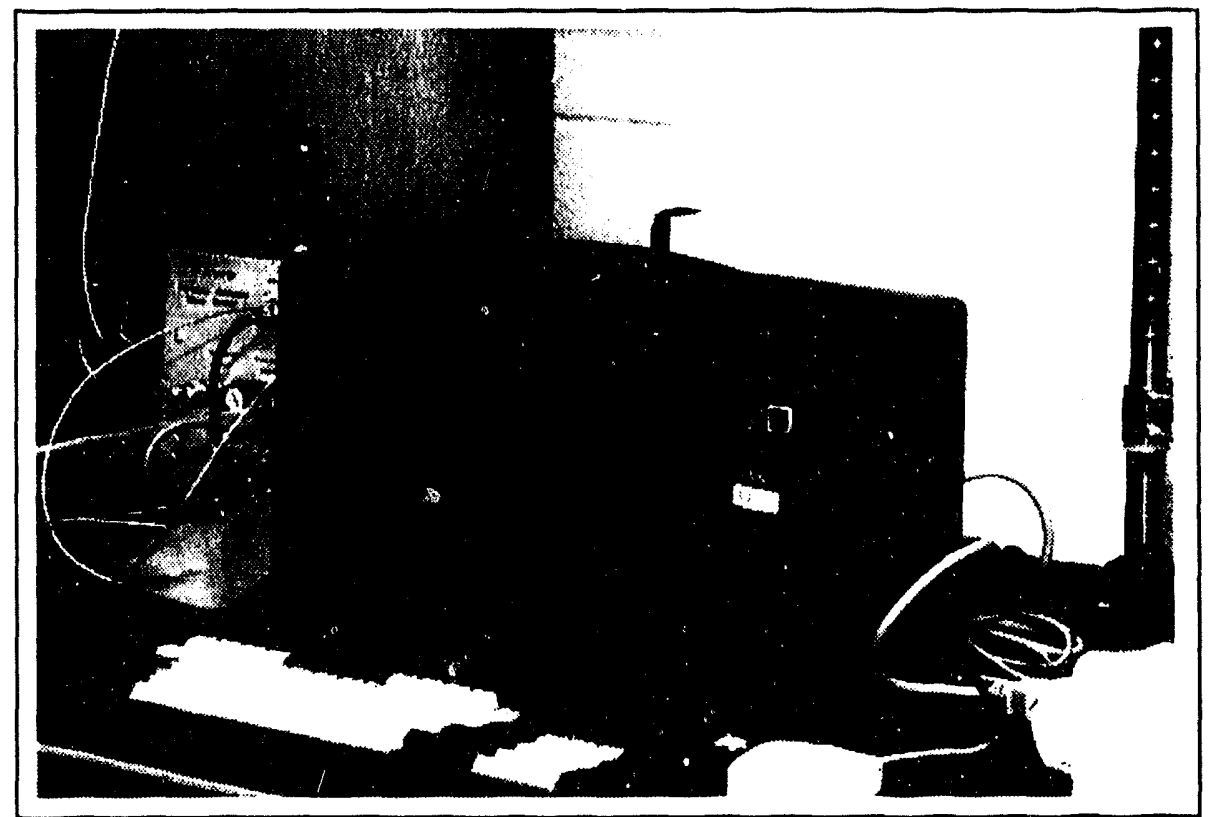

Figure 2.2. The portable acoustic wave sensor.

currently used in the DOE weapons complex will eventually be regulated. It is the goal of the production agencies to eliminate their use from weapons manufacturing. In addition, the new Clean Air Act and other Federal, state, and local regulations provide stricter regulations regarding all chemical emissions (e.g., volatile organic compounds) to the environment and emphasize the need to monitor and document these emissions. 


\section{TASK DESCRIPTION}

Cleaning alternative activities are identifying cleaning processes which are environment, safety and health-friendly and produce zero or near zero waste discharge. The project began in FY90 by identifying and evaluating currently available cleaning technologies, including substitute solvents to be used to clean electronic assemblies. This selection was based on a cleaning efficacy study and an accelerated aging study of cleaned substrates. Six solvents were evaluated (two aqueous-based, one terpene-based, one alkyl acetate, one alcohol. and a trichloroethylene/ isopropyl alcohol baseline). The efficiency with which these solvents removed rosin flux and silicone mold release were determined using Auger electron spectroscopy, contact angle measurements, and ionic conductivity measurements on substrate rinse solutions. In addition, the use of water soluble organic acid fluxes that can be cleaned with distilled water rinses was similarly evaluated. Cleaned substrates were subjected to accelerated aging at elevated temperatures and humidities. Based on the evaluations, aqueous cleaners and d-limonene appear to be the most likely candidates for cleaners in the long term. Aqueous cleaners are inherently safe to use and under most current regulations are relatively easy to dispose. D-limonene, implemented as the immediate substitute cleaner for replacing halogenated cleaners for electronic assembiies at the Kansas City Plant, also offers potential as a long term solution since it may be able to be recycled through low temperature vacuum distillation.

\section{TECHNOLOGY NEEDS}

CFC and CHC solvents are used throughout the DOE weapons complex for cleaning processes. However, due to regulatory requirements, CFCs will be phased out by 1995. SNL and the Allied Signal Aerospace-Kansas City Division (AS$\mathrm{KCD}$ ) have committed to implement non-CFC cleaners by 1995 . This task plan is an essential part of the ECMID at AS-KCD. Solvent substitution technologies will be evaluated and applied to the fabrication of selected demonstration components at $\mathrm{AS}-\mathrm{KCD}$.

\section{ACCOMPLISHMENTS}

- Established parameters to distill d-limonene from used cleaner, a mixture of d-limonene and isopropyl alcohol (IA).

- Fabricated ten "Pulse Width Modulator" boards for a Simple Firing Set with nonrosin flux and IA cleaned.

- Completed corrosion mechanism study on brass in alkaline medium.

- Successfully assisted RSM Electron Power to replace Freon cleaning using $d$ limonene and ethyl lactate. 


\section{4 \\ SUPERCRITICAL CARBON \\ DIOXIDE CLEANING}

\section{TASK DESCRIPTION}

The overall goal of this program is to investigate the feasibility of replacing toxic and environmentally-objecticiable volatile organic cleaning solvents with supercritical carbon dioxide $\left(\mathrm{SC}-\mathrm{CO}_{2}\right)$ in the DOE Complex; develop an environmentally conscious cleaning process that does not add to the solvent waste stream and can therefore be used in the long term; and engineer cleaning systems that can be implemented within the Complex. The potential advantages of SC$\mathrm{CO}_{2}$ cleaning are enorrnous; $\mathrm{CO}_{2}$ is nontoxic, recyclable, and relatively inexpensive. One of the positive aspects of $\mathrm{SC}-\mathrm{CO}_{2}$ is that it is recyclable. Figure 2.4 is a schematic of an ideal SC- $\mathrm{CO}_{2}$ cleaning system. The parts to be cleaned are placed in the extractor and the $\mathrm{CO}_{2}$ circulates through the pressure reducer and separator, and is recycled back to the extractor. Because the dissolving power of $\mathrm{CO}_{2}$ generally decreases as the pressure is decreased (at constant temperature), the contaminant is collected in the separator. SC$\mathrm{CO}_{2}$ will prove most useful where parts having complicated geometry must be cleaned and no other method is adequate. The use of SC- $\mathrm{CO}_{2}$ as a cleaner is consistent with DOE's stated goals regarding waste minimization, CFC elimination of worker exposure to toxic solvents, and compliance with environmental regulations.

\section{TECHNOLOGY NEEDS}

Supercritical $\mathrm{CO}_{2}$ cleaning features waste minimization through a recycle process, elimination of CFC and halogenated solvent usage, and 
- Completed parts (printed wiring boards, resistors, capacitors, diodes, transistors) testing with $\mathrm{SC}-\mathrm{CO}_{2}$.

\section{COLLABORATION/TECHNOLOGY} TRANSFER

Technology transfer between SNL and AS-KCD will occur naturally as a result of the nature of the ECMID. Participation in the Solvent Waste Stream Working Groups will also facilitate discussion and transfer among members of the DOE manufacturing complex. Technology transfer to members of private industry will occur as a result of technical presentations at meetings with the Joint Association for the Advancement of Supercritical Fluid Technology (JAAST).
For further information, please contact:

\section{Carol Adkins}

Principal Investigator

Sandia National Laboratory

(505) 845-9119

\section{George C. Allen}

Technical Program Manager

Sandia National Laboratory

(505) 844-9769 


\section{TASK DESCRIPTION}

This activity recommends development of leadfree solder alloy pastes which may be used in environmentally acceptable circuit assembly by means of surface mound technology. The subtasks involve alloy design and selection, preparation of ultrafine solder alloy powders, conversion of powders to paste, evaluation of alloy wetting characteristics, solder assembly and performance evaluation of test vehicles, and demonstration of the feasibility of ECM on development hardware and transfer of this technology to U.S. industry and war reserve production. In addition to being environmentally safe, the ultrafine powders produced during this project will enable manufacture of printed wiring boards having considerably finer pitch to meet the challenge of today's shrinking microcircuit technologies. Successful completion of this project will ease public anxiety over lead use in manufactoring, and assist U.S. industry in being more competitive in world markets.

\section{TECHNOLOGY NEEDS}

Lead metal and its compounds are known toxins, and legislation in both Houses of Congress is staged to ban or heavily tax lead use in all commercial products. Since lead is a component of electronic solder alloys, U.S. electronic manufacturers are concerned that this legislation will unnecessarily burden the industry, which is already reeling from intense overseas competi-

tion. This program is developing lead free solder alloy pastes, which may be used in environmentally-acceptable circuit assemblies.

\section{ACCOMPLISHMENTS}

- Identified initial lead-free solder candidates by characterization of melting behavior and microstructure of small ingot samples.

- Characterized solder alloy performance in wetting, mechanical strength, ductility, and thermal fatigue.

- Optimized high-pressure gas atomization process for production of fine leadfree solder alloy powder.

\section{COLLABORATION/TECHNOLOGY TRANSFER}

The technologies will be available to DOE design and production facilities, subcontractors, other government agencies, and the commercial sector. Technology transfer will be handled through SNL's Technology Transfer Center. Site visits, technical presentations, and documentation in open literature will also facilitate technology transfer. 


\section{For further information, please contact:}

\section{Fred Yost}

Principal Investigator

Sandia National Laboratory

(505) 844-5278

\section{George C. Allen}

Technical Program Manager

Sandia National Laboratory

(505) 844-9769

\section{Iver Anderson}

Principal Investigator

Ames Laboratory

Iowa State University

(515) 294-8252

\section{J.P. Corones}

Technical Program Manager

Ames Laboratory

Iowa State University

(515) 294-9636 


\subsection{ENVIRONMENTALLY CONSCIOUS MANUFACTURING HARDWARE VALIDATION}

\section{TASK DESCRIPTION}

Technologies and materials developed in the laboratory are transferred to the Kansas City Plant (KCP) for integration into a manufacturing pilot operation, prior to introducing changes to the factory floor, to evaluate product quality and manufacturing system issues. Tech-nologies selected for a specific application affect many elements of the product and the total manufacturing process. A technology cannot be isolated as its application depends on the product design and upstream manufacturing processes, and its implementation affects downstream processes.

Technology demonstration activities at the $\mathrm{KCP}$ are designed to insure applicability of a technology to the production process. Aspects of the substitute process that require evaluation include worker exposure to new chemicals; safety and reliability of the new process; new waste streams in terms of toxicity and volume; material compatibility; component functionality, quality and long-term reliability; and component manufacturability including throughput and cost.

Aging, corrosion and compatibility is being evaluated to insure residues left by a new cleaning method does not react unfavorably with the substrate or encapsulant thereby decreasing component reliability. Manufacturability is tested in a system context with regard to throughput, quality, and subsequent processing capability (i.e., can a cleaned substrate be properly welded, soldered, encapsulated, etc.). The finished component is functionally tested to insure proper operation after being subjected to various environments it may be exposed to during its lifetime including humidity, thermal cycling, shock, and vibration. Without qualification of these materials and processes, and insurance of long term functionality and reliability of war reserve weapons, they will not be used in manufacturing and no benefit will be gained from the program.

\section{TECHNOLOGY NEEDS}

The validation of ECM hardware effort is necessary to ensure that the electronic components manufactured using environmentally clean manufacturing techniques and materials will perform their design function in the same manner as the original design.

\section{ACCOMPLISHMENTS}

- Completed all Tool Made Sample (TMS)-type testing.

- Completed statistical analysis of ECMID data versus TMS data. 


\section{COLLABORATION/TECHNOLOGY TRANSFER}

The technologies will be available to DOE design and production facilities, subcontractors, other government agencies, and the commercial sector. Technology transfer will be handled through SNL's Technology Transfer Center. Site visits, technical presentations, and documentation in open literature will also facilitate technology transfer.
For further information, please contact:

\section{Bill Ross}

Principal Investigator

Allied Signal Kansas City Division

(816) $997-4151$

David L. Jordan

Technical Program Manager

Allied Signal Kansas City Division

(816) 997-3318 


\section{TASK DESCRIPTION}

The manufacturing techniques required to fabricate large-scale electronic assemblies differ somewhat from the techniques used to fabricate lower scale assemblies. This project builds on the knowledge obtained during the MC4138 Programmer study in FY92 by including those processes used at the higher assembly levels that are not used at the lower levels, and further studying those processes used at both levels.

The B61-6/8 electronic assembly (programmer) was the prototype assembly manufactured with no hazardous materials and minimal waste generated (see Figure 2.7). It is the first ECM unit manufactured with ECM materials and processes. Criteria for materials selected for the prototype programmer were printed wiring boards (nonMDA cured), polymers (non-isocyanate and nonMDA), solvents (non-CHC/CFC), and plating (non-cyanide, non-hexavalent chromium). Processes that generate minimal waste were used to manufacture the assembly to prove the feasibility and capability of the component. If ECM materials and processes prove to function as designed, the technology will be transferred to other electronic hardware and assemblies until all weapon systems components are manufactured using ECM technologies.

The information gained on this project will greatly assist in the goal of developing processes and materials necessary to enable the manufacture of environmentally clean systems at the $\mathrm{KCP}$. Both electronic and mechanical assemblies will be included in this project in addition to the cleaning methods required for both. The techniques and processes validated on this project will then be available to other programs to assist in elimination of $\mathrm{CFCs}, \mathrm{CHCs}$ and other hazardous materials from all aspects of manufacturing and assembly.

\section{TECHNOLOGY NEED}

The electronic assembly effort is necessary to ensure that the programmers manufactured using environmentally clean manufacturing techniques and materials will perform their design function in the same manner as the original design.

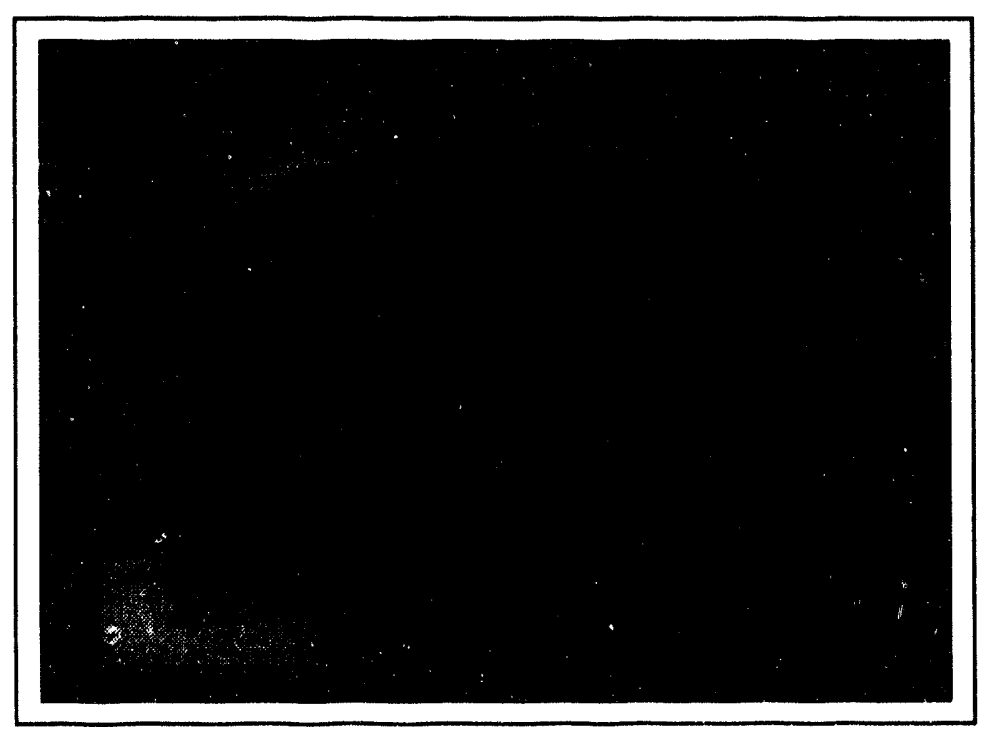

Figure 2.7. The B61-6/8 Electronic 


\section{ACCOMPLISHMENTS}

- Implemented ECM technologies in the manufacture of three functional demonstration B61 programmers at Allied Signal-Kansas City Division.

- Identified all hazardous product/process materials.

- Identified non-hazardous substitutes.
For further information, please contact:

\section{Bill Ross}

Principal Investigator

Allied Signal Kansas City Division

(816) $997-4151$

\section{David L. Jordan}

Technical Program Manager

Allied Signal Kansas City Division

(505) 997-3318

\section{COLLABORATION/TECHNOLOGY TRANSFER}

The technologies will be available to DOE design and production facilities, subcontractors, other government agencies, and the commercial sector. Technology transfer will be handled through SNL's Technology Transfer Center. Site visits, technical presentations, and documentation in open literature will also facilitate technology transfer. 


\section{Waste Component Recycle, Treatment, and Disposal Integrated Demonstration Overview}

\section{Section 3.0}




\subsection{WASTE COMPONENT RECYCLE, TREATMENT, AND DISPOSAL INTEGRATED DEMONSTRATION OVERVIEW}

The Waste Component Recycle, Treatment, and Disposal Integrated Demonstration (WeDID) is addressing the process of disposal of waste from weapons dismantlement (see Figure 3.0a). The process includes waste identification, minimization, treatment, transportation, and ultimate disposal. It focuses on Sandia-designed weapon components, balancing available technologies for waste characterization, treatment, and disposal (see Figure 3.0b). It is also exploring the acceptability of these technologies, as well as security declassification technologies, in the context of current and expected regulations for hazardous and radioactive waste disposal. In performing the integrated demonstration, waste treatment technologies will be assessed and tested for their applicability to weapons dismantlement wastes. As the third dimension of the demonstration, many technologies investigated for disposing of the hazardous materials found in the Sandia-designed components can be applied to the similar critical disposal problem now faced by U.S. and foreign electronics manufacturers. This demonstration is being conducted in close collaboration with DOE-Defense Programs and will draw upon the expertise found within the DOE Complex and private industry.

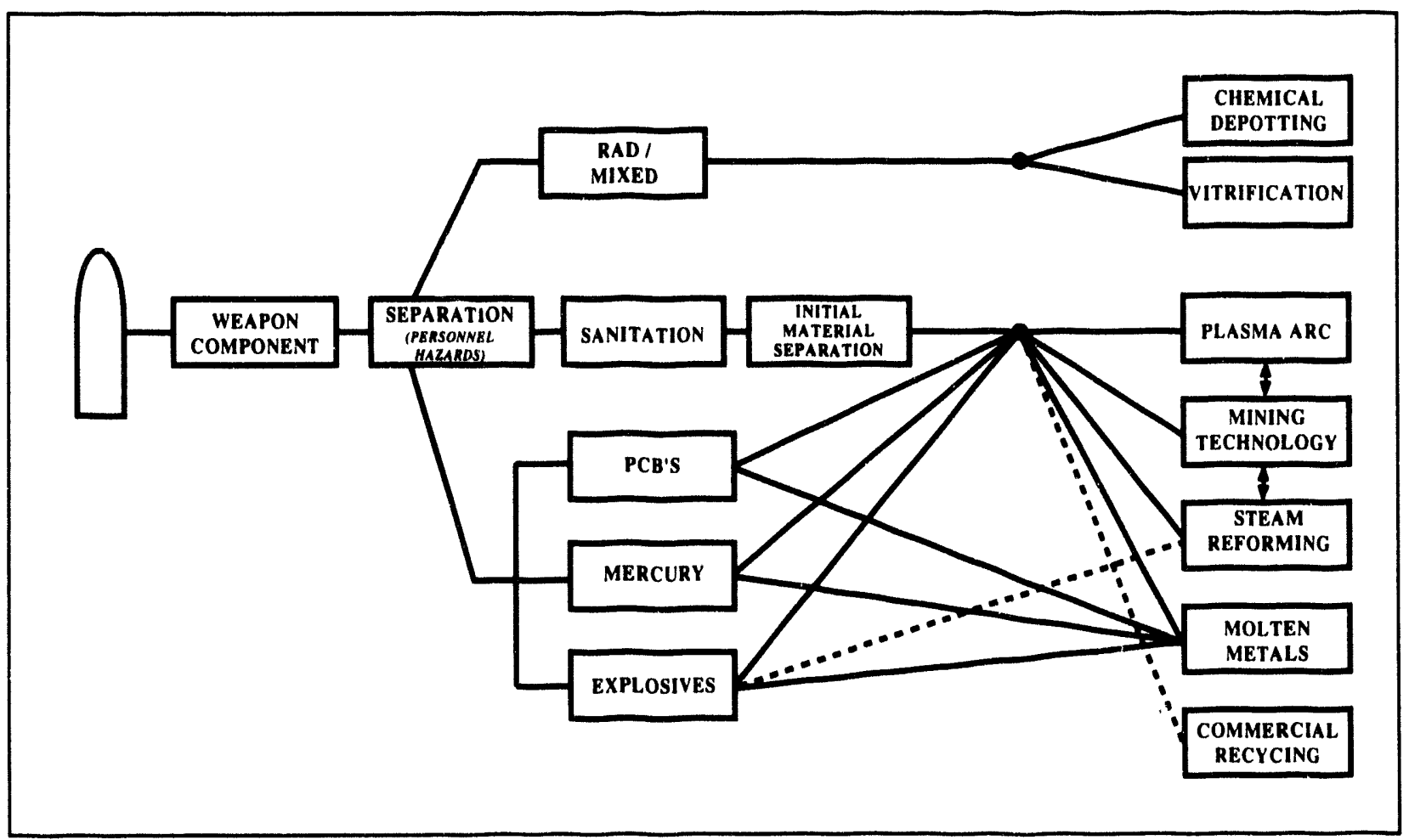

Figure 3.0a. WeDID Directions Treatment Technology Wiring Diagram. 
The task is demonstrating pretreatment technologies, such as the forge hammer and hazard separation technologies, that can be used to prepare weapon components for further treatment, recycling, and sanitization. Additionally, the program will work with treatment technology facilities to enable regulatory compliance, demonstrate cost-effective techniques, such as precious metals recovery and recycling, and near-term treatment technology system solutions that can be used by DOE for the disposal of weapon components. A discussion of the various tasks follows.

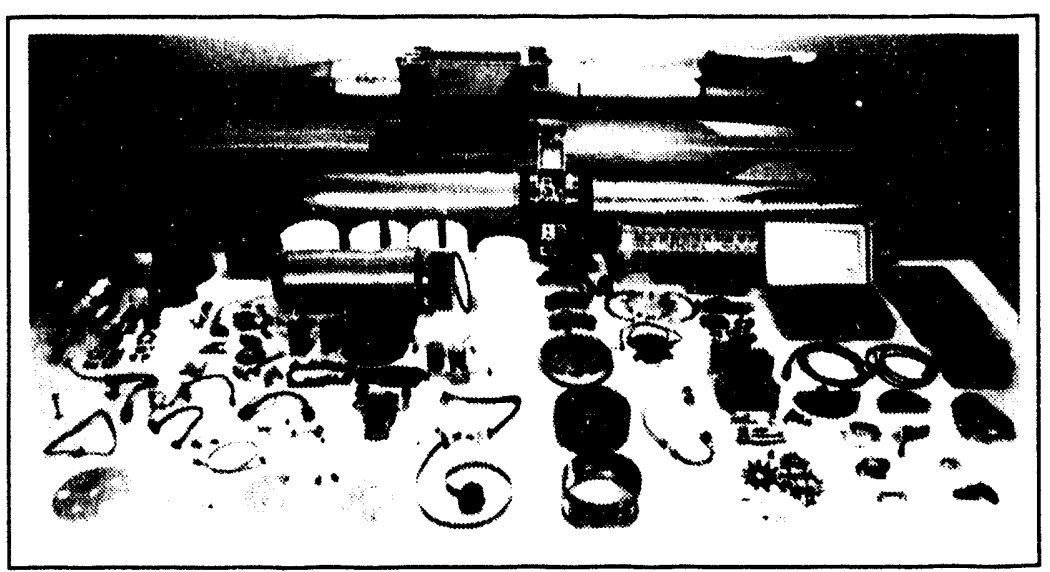

Figure 3.0b. Disassembled Sandia-designed Nuclear Weapon. 


\section{TASK DESCRIPTION}

The forge hammer is a pretreatment technology designed to rapidly rubblize nuclear weapon components (see Figure 3.1). This rubblization process allows for easier chemical characterization and subsequent treatment, or separation of metals. However, there is a desire, for waste minimization reasons, to ensure that dissimilar materials are not rubblized. Therefore, it will include an interlock system using bar-coding to identify components, and prevent creating mixed waste by not rubblizing components containing radioactive material and heavy metals. Remote operation and dust control systems have been installed to address worker safety and health problems.

\section{TECHNOLOGY NEEDS}

Approximately 2,000 weapons per year will be decommissioned, requiring treatment of approximately 230 cubic meters of weapons components and associated declassifications per year. Nuclear weapon components cannot legally be disposed of in conventional landfills without pretreatment or extensive characterization because they contain leachable toxic substances, like lead and cadmium. Weapons components also routinely contain radioactive, explosive, and toxic materials that are not easily separated or characterized. In addition, regulations are becoming increasingly stringent in terms of dis- posal options, necessitating environmentally sound practices. Chemical characterization of weapon components is prohibitively expensive. With the increasingly stringent regulatory environment, there is a need for treatment technology systems that can meet all regulatory requirements now and in the future. At the same time, these treatment technology systems must reduce front-end characterization activities, and, wherever possible, provide significant recycling opportunities. Technologically robust technology systems can save DOE both money and time in the treatment and disposal of nuclear weapons components or electronic materials.

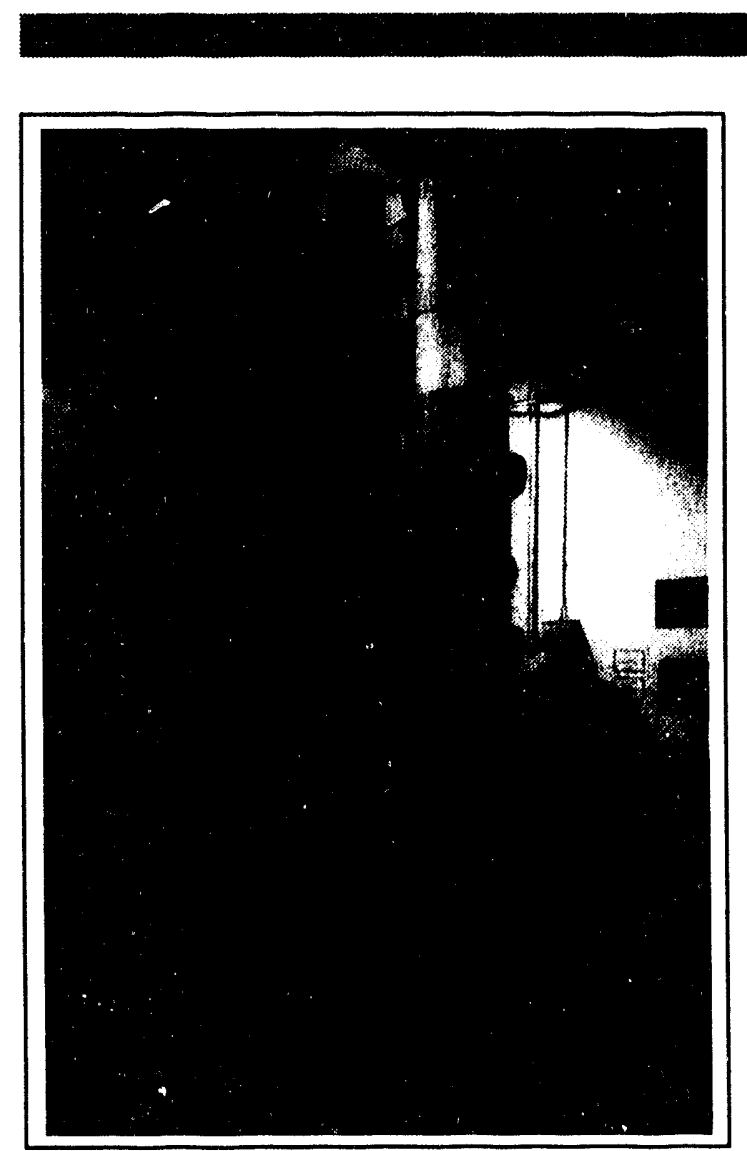

Figure 3.1. Forge Hammer. 


\section{ACCOMPLISHMENTS}

- Three forge hammers procured from DoD surplus at essentially no cost (only cost for shipping) to DOE.

- Forge hanumers delivered to Allied Signal-Kansas City Division, Pantex Plant, and Sandia National Laboratory.

- New rubblization box demonstrated, including dust control system.

- Forge hammer material rubblization and cryogenic fracture demonstrated.

- Developed test plans for forge hammer, interlock, and dust control system.

\section{COLLABORATION/TECHNOLOGY TRANSFER}

Technology transfer has occurred between the Sandia National Laboratory, the Pantex Plant, and the Allied Signal Kansas City Plant. This has benefitted the WeDID program by collaborating among the facilities and integrating the program elements/technologies into a systems approach to maximize program coordination. Further, the forge hammer interlock and dust control systems are likely to be able to be patented as process patents. This would allow transferring of the technology to private industry through CRADAs.

\section{For further information, please contact:}

\author{
W. Ted Wheelis
}

Principal Investigator

Sandia National Laboratory

(505) 845-9298

\section{George C. Allen}

Technical Program Manager

Sandia National Laboratory

(505) 844-9769

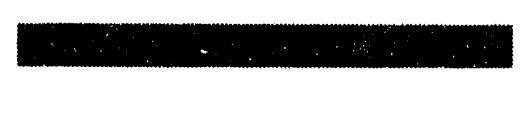




\section{TASK DESCRIPTION}

It is advantageous to separate waste streams as early as possible in a process to minimize the amount of a particular material (i.e., waste minimization) for subsequent processing and to keep one material from contaminating other recovery or processing steps. Standard cutting procedures, like bandsaws or shears, when used on nuclear weapon components, are generally difficult to use, are slow, and are not very accurate (i.e., wide cutting margins are required to account for errors or failures of the cutting devices), and, therefore, do not minimize waste. To overcome these disadvantages, WeDID is demonstrating the use of water-jet cutting techniques. Specifically, water-jet cutting can cut through thick, heterogeneous materials quickly, does not appreciably heat up the material being cut (important for potting that may evolve carcinogens when heat up), is essentially vibration free, and can cut intricate patterns within thousandths of an inch of a target material. In addition, because the cutting medium is water and garnet (i.e., sand), cleanup is straightforward (i.e., mechanical filtration). This technology has been demonstrated in the WeDID program for the removal of thermal batteries from potted components and for the demilitarization of a parachute (see Figure 3.2). For example, it took just a few minutes to remove the thermal batteries and to cut through a 12 -inch diameter section of nylon/Kevlar parachute. Water-jet cutting lends itself to small, enclosed systems that recycle the water used for cutting and could be used for explosive or radioactive materials removal where containment boundaries are needed. The waterjet system will be combined with an $\mathrm{x}$-ray system to ensure the location of hazards to be removed is accurately known (critical information since potting can cause items to shift positions in nuclear weapon components). Eventually, a full-scale weapon component hazard separation system (including water-jet, $x$ ray, visual, and control systems) will be demonstrated.

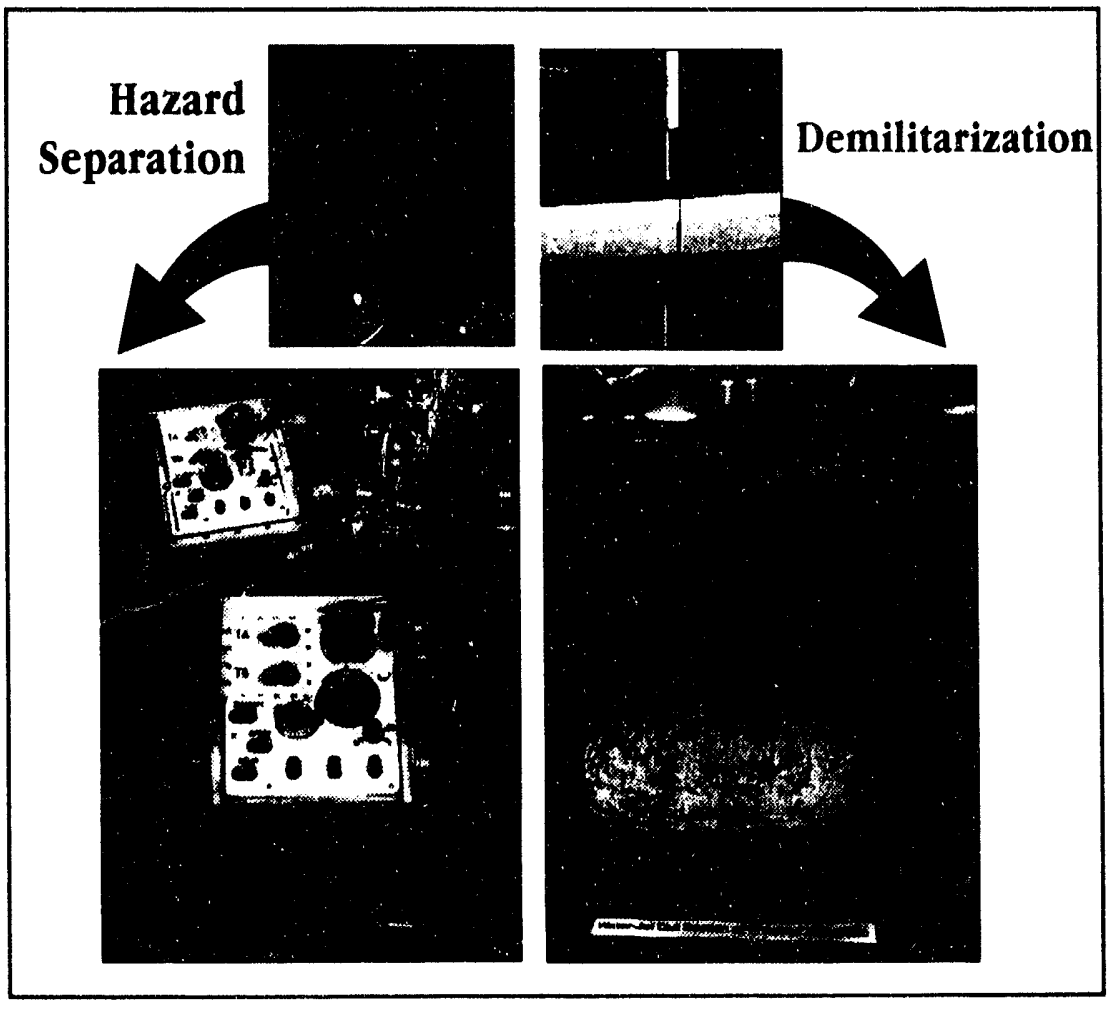

Figure 3.2. Demilitarization. 


\section{TECHNOLOGY NEEDS}

Nuclear weapon components cannot legally be disposed of in conventional landfills without pretreatment or extensive characterization because they contain leachable toxic substances, like lead and cadmium. Weapons components also routinely contain radioactive, explosive, and toxic materials that are not easily separated or characterized. In addition, regulations are becoming increasingly stringent in terms of disposal options, necessitating environmentally sound practices. Technologically robust treatment systems can save DOE both money and time in the treatment and disposal of nuclear weapons components or electronic materials.

\section{ACCOMPLISHMENTS}

- Procured water-jet cutting system, Xray system, and control hardware.

- Demonstrated hazard separation by water-jet cutting system removal of thermal battery from pre-flight control unit.

- Provided parachute demilitarization/disposal guidance to Pantex Plant.

- Demonstrated parachute water-jet cutting demilitarization.

- Demonstrated water-jet cutting technique for kevlar recycling and identified commercial recycler for kevlar.

- Identified recycle industry drivers of separation, aluminum, and organics.

- Identified precious metals recovery options in weapon components.
- Demonstrated the feasibility of using digitized X-rays to drive a water-jet cutting system for removal of hidden hazards, like radioactive gap tubes.

- Developed test plans for hazard separation system.

\section{COLLABORATION/TECHNOLOGY TRANSFER}

Collaboration and technology transfer has occurred between the Sandia National Laboratory, the Pantex Plant, and the Allied Signal Kansas City Plant. This has benefitted the WeDID program by collaborating among the facilities and integrating the program elements/ technologies into a systems approach to maximize program coordination. Further, the waterjet cutting system is likely to be able to be patented as a process patent. This would allow transferring of the technology to private industry through CRADAs.

\section{For further information, please contact:}

\section{W. Ted Wheelis}

Principal Investigator

Sandia National Laboratory

(505) 845-9298

\section{George C. Allen}

Technical Program Manager

Sandia National Laboratory

(505) 844-9769 


\subsection{ADVANCED TREATMENT TECHNOLOGIES}

\section{TASK DESCRIPTION}

Plasma arc is one of the advanced treatment technologies in the Waste Component Recycle,

Treatment, and Disposal Integrated Demonstration. It demonstrates the destruction of organic materials and recycling of the metals (precious and bulk) found in the weapons (see Figure 3.3a). Plasma arc operates at extremely high temperatures and is able to destroy any hazardous organic material. A natural product of a plasma arc system is a metal ingot. The ingot is typically made up of a high concentration of copper which collects precious metals like gold, silver, and palladium. Another
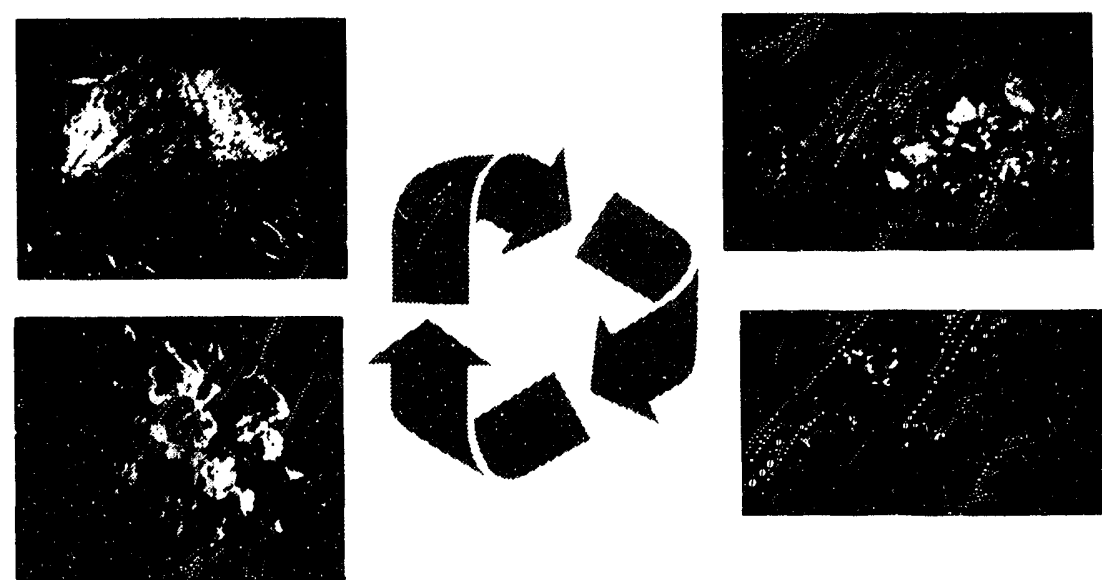

Figure 3.3b. Recycling potential of weapon treatment processes. product of the process is a glassified "slag" which in turn collects undesirable metals, such as cadmium and arsenic, and other materials, like asbestos.

Figure 3.3a. Electronic components before and after thermal

Steam reforming is an advanced treatment technology that demonstrates destruction of organic materials found in weapons by using a steam reforming unit (see Figure 3.3b). After organic destruction, the residues, typically metals and ceramics, can be further recycled using separation techniques to increase the value of the recyclable material. This method is principally being used for organics destruction; therefore, other items, such as classified foams, will also be examined as another use for the process. 
Mining separation technologies are advanced treatments using commercial mining techniques demonstrating the selective removal of material from weapon components to maximize the recyclable/sellable potential of the metals. In this process, the weapon component material is partitioned into fractions of aluminum, ferromagnetic, precious metal bearing and organic combinations, and predominantly organic fines. This method is concentrating on showing separation of the valuable fractions of a weapon component, as well as providing actual data on the assayed economic value of the precious metals recovered.

Molten metals is an advanced treatment technology that is demonstrating destruction of organics for recovery of precious and bulk metals. Molten metals operates on the principle of a molten bath of a metal such as iron, although it can be customized to include copper or aluminum. Material for treatment is injected through the molten bath to ensure good mixing as well as optimum heat transfer. Metal found in weapon cornponents goes into the metal bath and can be drained off into ingot form for further processing $\mathrm{cr}$ recycling. Molten metals is also being evaluated as to its capability to treat explosives found in weapons.

Chamical depotting is an advanced treatment ter:hnology being used to declassify protected volume parts and classified electronic weapon components containing recyclable metals and either radioactive gap tubes or other types of hazardous components. The process dissolves or attacks a wide range of organic adhesives, sealants, coatings and potting compounds (encapsulants), is non-corrosive and biodegradable. The process is being used at the Kansas City Plant to facilitate removal of radioactive gap tubes from units which presently would constitute mixed waste.

\section{TECHNOLOGY NEEDS}

Approximately 2,000 weapons per year will be decommissioned, requiring treatment of approximately 230 cubic meters of weapons components and associated declassifications per year. Chemical characterization of weapon components is prohibitively expensive. With the increasingly stringent regulatory environment, there is a need for treatment technology systems that can meet all regulatory requirements now and in the future. Technologically robust treatment systems can save DOE both money and time in the treatment and disposal of nuclear weapons components or electronic materials.

\section{ACCOMPLISHMENTS}

- Completed printed circuit board treatment technology demonstrations using acid digestion, steam reforming, vitrification, and plasma arc.

- Demonstrated treatment of four weapons components (fire set, radar, filter pack, and pre-flight control unit) by steam reforming.

- Established independent treatment technology support group from industry and academic personnel.

- Demonstrated steam reforming destruction of kevlar/nylon parachute.

- Completed bench-scale demonstration of approximately 5 pounds of weapon components at Molten Metals Technology.

- Developed test plans for the advanced treatment technologies.

- Completed demonstration of plasma arc on thermal battery containing asbestos. 
- Developed cost effectiveness methodology for treatment technologies.

- Completed draft regulatory framework document.

- Completed analysis of current disposal methods versus vitrification over a ten year life cycle.

- Demonstrated destruction by steam reforming of surrogate classified foam.

- Developed test plans for advanced treatment technologies.

\section{COLLABORATION/TECHNOLOGY TRANSFER}

Collaboration and technology transfer has occurred between the Sandia National Laboratory, the Pantex Plant, and the Allied Signal at the Kansas City Plant. This has benefitted parachute demilitarization at Pantex, and demonstration destruction of classified waste surrogate using steam reforming for Kansas City Plant. Steam reforming is being demonstrated by Synthetica Technologies, Inc., a commercial firm in San Francisco. Molten metals activities are being conducted by Molten Metal Technology in Massachusetts. Plasma Arc is being demonstrated by Mason \& Hanger PEAT in Huntsville, Alabama. Mining technology is being conducted by the U.S. Bureau of Mines.
For further information, please contact:

Dale M. Blankenship

Principal Investigator

Sandia National Laboratory

(505) 844-9694

\section{James D. Lutz}

Principal Investigator

Sandia National Laboratory

(505) 844-9082

\section{George C. Allen}

Technical Program Manager

Sandia National Laboratory

(505) 844-9769

\section{Robert S. Sanders}

Principal Investigator

Allied Signal/Kansas City Plant

(816) $997-4694$

\section{David L. Jordan}

Technical Program Manager Allied Signal/Kansas City Plant (816) $997-3318$ 


\section{How To Get Involved}

Section 4.0 


\section{WORKING WITH THE DOE OFFICE OF ENVIRONMENTAL RESTORATION AND WASTE MANAGEMENT}

DOE provides a range of programs and services to assist universities, industry, and other privatesector organizations and individuals interested in developing or applying environmental technologies. Working with DOE Operations Offices and management and operating contractors, EM uses conventional and innovative mechanisms to identify, integrate, develop, and adapt promising emerging technologies. These mechanisms include contracting and collaborative arrangements, procurement provisions, licensing of technology, consulting arrangements, reimbursable work for industry, and special consideration for small business.

\section{Cooperative Research and Development Agreements (CRADAs)}

EM will facilitate the development of subcontracts, R\&D contracts, and cooperative agreements to work collaboratively with the private sector.

EM uses CRADAs as an incentive for collaborative R\&D. CRADAs are agreements between a DOE $R \& D$ laboratory and any non-Federal source to conduct cooperative $R \& D$ that is consistent with the laboratory's mission. The partner may provide funds, facilities, people, or other resources. DOE provides the CRADA partner access to facilities and expertise; however, no Federal funds are provided to external participants. Rights to inventions and other intellectual property are negotiated between the laboratory and participant, and certain data that are generated may be protected for up to 5 years.

Consortia will also be considered for situations where several companies will be combining their resources to address a common technical problem. Leveraging of funds to implement a consortium can offer a synergism to overall program effectiveness.

\section{Procurement Mechanisms}

DOE EM has developed an environmental management technology development acquisition policy and strategy that uses phased procurements to span the RDDT\&E continuum from applied R\&D concept feasibility through full-scale remediation. DOE EM phased procurements make provisions for unsolicited proposals but formal solicitations are the preferred responses. The principle contractual mechanisms used by EM for industrial and academic response include Research Opportunity Announcements (ROAs) and Program R\&D Announcements (PRDAs). In general, EM Technology Development uses ROAs to solicit proposals for R\&D projects and PRDAs for proposals for its DT\&E projects. 
EM uses the ROA to solicit advanced research and technologies for a broad range of cleanup needs. The ROA supports applied research ranging from concept feasibility through full-scale demonstration. In addition, the ROA is open continuously for a full year following the date of issue and includes a partial procurement set-aside for small businesses. Typically, ROAs are published annually in the Federal Register and the Commerce Business Daily, and multiple awards are made.

PRDAs are program announcements used to solicit a broad mix of R\&D and DT\&E proposals. Typically, a PRDA is used to solicit proposals for a wide-range of technical solutions to specific EM problem areas. PRDAs may be used to solicit proposals for contracts, grants, or cooperative agreements. Multiple awards, which may have dissimilar approaches or concepts, are generally made. Numerous PRDAs may be issued each year.

In addition to PRDAs and ROAs, EM uses financial assistance awards when the technology is developed for public purpose. Financial assistance awards are solicited through publication in the Federal Register. These announcements are called Program Rules. A Program Rule can either be a one-time solicitation or an open-ended, general solicitation with annual or more frequent announcements concerning specific funding availability and desired R\&D agreements. The Program Rule can also be used to award both grants and cooperative agreements.

EM awards grants and cooperative agreements if fifty-one percent or more of the overall value of the effort is related to a public interest goal. Such goals include possible non-DOE or other Federal agency participation and use, advancement of present and future U.S. capabilities in domestic and international environmental cleanup markets, technology transfer, advancement of scientific knowledge, and education and training of individuals and business entities to advance U.S. remediation capabilities.

\section{Licensing of Technology}

DOE contractor-operated laboratories can license DOE/EM-developed technology and software to which they elect to take title. In other situations where DOE owns title to the resultant inventions, DOE's Office of General Counsel will do the licensing. Licensing activities are done within existing DOE intellectual property provisions.

\section{Technical Personnel Exchange Assignments}

Personnel exchanges provide opportunities for industrial and laboratory scientists to work together at various sites on environmental restoration and waste management technical problems of mutual interest. Industry is expected to contribute substantial cost-sharing for these personnel exchanges. To encourage such collaboration, the rights to any resulting patents go to the private sector company. These exchanges, which can last from 3 to 6 months, are opportunities for the laboratories and industry to better understand the differing operating cultures, and are an ideal mechanism for transferring technical skills and knowledge. 


\title{
Consulting Arrangements
}

Laboratory scientists and engineers are available to consult in their areas of technical expertise. Most contractors operating laboratories have consulting provisions. Laboratory employees who wish to consult can sign non-disclosure agreements, and are encouraged to do so.

\section{Reimbursable Work for Industry}

DOE laboratories are available to perform work for industry, or other Federal agencies, as long as the work pertains to the mission of a respective laboratory and does not compete with the private sector.

The special technical capabilities and unique facilities at DOE laboratories are an incentive for the private sector to use DOE's facilities and contractors expertise in this reimbursable work for industry mode. An advanced class patent waiver gives ownership of any inventions resulting from the research to the participating private sector company.

\section{EM Small Business Technology Integration Program}

The EM Small Business Technology Integration Program (SB-TIP) seeks the participation of small businesses in the EM Research, Development, Demonstration, Testing and Evaluation programs. Through workshops and frequent communication, the EM SB-TIP provides information on opportunities for funding and collaborative efforts relative to advancing technologies for DOE environmental restoration and waste management applications.

EM SB-TIP has established a special EM procurement set aside for small firms (500 employees or less) to be used for applied research projects, through its ROA. The program also serves as the EM liaison to the DOE Small Business Innovation Research (SBIR) Program Office, and interfaces with other DOE small business offices, as well.

\section{CONTACT}

\author{
David W. Geiser, Acting Director \\ International Technology Exchange Division \\ EM-523 \\ Environmental Restoration and Waste \\ Management Technology Development \\ Washington, D.C. 20585 \\ (301) $903-7940$
}




\section{EM Central Point of Contact}

The EM Central Point of Contact is designed to provide ready access to prospective research and business opportunities in waste management, environmental restoration, and decontamination and decommissioning activities, as well as information on EM-50 IPs and IDs. The EM Central Point of Contact can identify links between industry technologies and program needs, and provides potential partners with a connection to an extensive complex-wide network of DOE Headquarters and field program contacts.

The EM Central Point of Contact is the best single source of information for private-sector technology developers looking to collaborate with EM scientists and engineers. It provides a real-time information referral service to expedite and monitor private-sector interaction with EM.

To reach the EM Central Point of Contact, call 1-800-845-2096 during normal business hours (Eastern time).

\section{Office of Research and Technology Applications}

Office of Research and Technology Applications (ORTAs) serve as technology transfer agents at the Federal laboratories, and provide an internal coordination in the laboratory for technology transfer and an external point of contact for industry and universities. To fulfill this dual purpose, ORTAs license patents and coordinate technology transfer activities for the laboratory's scientific departments. They also facilitate one-on-one interactions between the laboratory's scientific personnel and technology recipients, and provide information on laboratory technologies with potential applications in private industry for state and local governments.

\section{For more information about these programs and services, please contact:}

\section{Claire Sink, Director}

Technology Integration Division

EM-521

Environmental Restoration and Waste

Management Technology Development

U.S. Department of Energy

Washington, D.C. 20585

(301) 903-7928 


\section{Acronyms}

Section 5.0 
AFCESA Air Force Civil Engineering Support Agency

AFESC Air Force Engineering Services Center

ASA-KCD Allied Signal Aerospace-Kansas City Division

CAA Clean Air Act

CFC chlorofluorocarbon

CRADA Cooperative Research and Development Agreements

CWA Clean Water Act

DoD Department of Defense

DOE Department of Energy

ECM Environmentally Conscious Manufacturing

EM Environmental Restoration and Waste Management

EPA Environmental Protection Agency

ES\&H Environment, Safety, and Health

IA isopropyl alcohol

ID Integrated Demonstrations

INEL Idaho National Engineering Laboratory

IP Integrated Programs

JAAST Joint Association for the Advancement of Supercritical Fluid Technology

KCP Kansas City Plant

LAFS laser ablative fluxless soldering

LANL Los Alamos National Laboratory

MOU Memorandum of Understanding

ORNL Oak Ridge National Laboratory

ORTAs Office of Research and Technology Applications 
OTD Office of Technology Development

PAWS portable acoustic wave sensor

PNL Pacific Northwest Laboratory

PRDA Program R\&D Announcements

RCRA Resource Conservation and Recovery Act

RDDT\&E Research, Development, Demonstration, Testing, and Evaluation

ROA Research Opportunity Announcements

SBIR Small Business Innovation Research

SB-TIP Small Business Technology Integration Program

SNL Sandia National Laboratory

TMS Tool Made Sample

WADR Waste Acid Detoxification and Reclamation project

WeDID Waste Component Recycle, Treatment \& Disposal Integrated Demonstration 

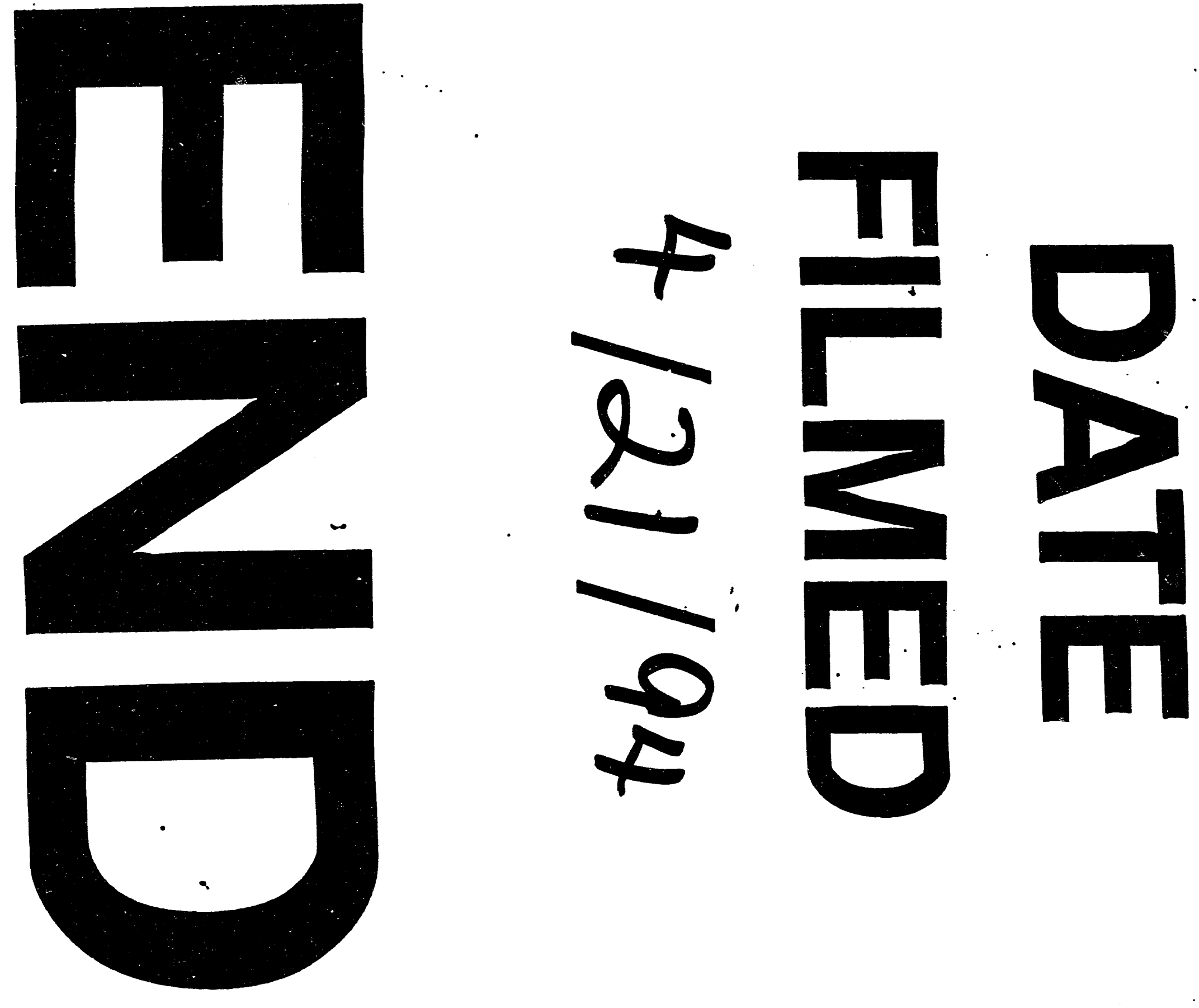
